\title{
ANALISIS KUALITAS PELAYANAN, PENANGANAN KOMPLAIN DAN CITRA RUMAH SAKIT TERHADAP KEPUASAN PENGGUNA KARTU BPJS DI RUMAH SAKIT DR. OEN SURAKARTA
}

\author{
Fildza Hashifa Tazkiya, Ida Aryati Diah Purnomo Wulan, Ratna Damayanti \\ Universitas Islam Batik Surakarta \\ shifa.tazkiya@gmail.com
}

\begin{abstract}
The research aims to identify and explain the effect either simultaneously or partially quality of service, complaint handling and image of the hospital against BPJS card user satisfaction in the hospital Dr. Oen Surakarta. This study uses a quantitative research design. The population is the entire card users BPJS in the hospital Dr. Oen Surakarta whose number is infinite. Samples of 100 respondents by sampling using purposive sampling method. A questionnaire was used for data retrieval. Data analysis techniques in this study using multiple linear regression analysis. The results showed that the $F$ test the quality of service, handling complaints and hospital image simultaneously and significantly affect user satisfaction BPJS card at the hospital Dr. Oen Surakarta. T-test results showed that the quality of services and significant impact on user satisfaction BPJS card. Handling complaints had no effect, and to the satisfaction of BPJS card users. the image of the hospital had no effect, and to the satisfaction of BPJS card users. The coefficient of determination indicates the quality of service, complaint handling and image of the hospital has the effect of 59\% of the card user satisfaction BPJS in the hospital Dr. Oen Surakarta.
\end{abstract}

Keywords: Quality of Service, Complaint Handling, Image Hospital, User Satisfaction BPJS Cards

\section{PENDAHULUAN}

Kesehatan merupakan salah satu insvestasi jangka panjang bagi setiap manusia, karena kesehatan termasuk kebutuhan hidup yang sangat penting dalam menunjang kegiatan sehari-hari. Pola hidup masyarakat yang berubah seiring dengan berkembangnya zaman memicu munculnya penyakit-penyakit baru yang disebabkan oleh perilaku mereka yang salah. Masyarakat yang awalnya hanya ingin mencoba untuk melakukan pola hidup yang sedang tren namun berlanjut menjadi sebuah kebiasaan yang dapat membahayakan kesehatannya, mereka hanya mengikuti apa yang dilihat tanpa mengetahui resiko yang akan diterima. Masyarakat baru akan menyadari rasiko dari kebisaan yang mereka lakukan setelah mendapat masalah pada kesehatannya.

Oleh sebab itu kebutuhan masyarakatakan pelayanan kesehatan terus meningkat dan beragam karena kini mereka sadar akan pentingnya kesehatan. Itulah mengapa kebutuhan akan prasarana kesehatan harus terus meningkat (Mongkaren, 2013). Tersedianya prasarana kesehatan mulai dari praktek dokter, puskesmas hingga rumah sakit milik pemerintah maupun wasta sangatlah membantu masyarakat untuk memeriksakan diri mereka (Sharon dan Santoso, 2017). 
Wiguna (2017) mengatakan, bahwa pada tanggal 1 Januari 2014 Indonesia telah mengesahkan program jaminan kesehatan yaitu Badan Penyelenggara Jaminan Sosial atau yang biasa disingkat BPJS, program ini diselenggarakan oleh badan hukum publik yang bertanggung jawab langsung kepada Presiden. BPJS dibagi menjadi dua yaitu BPJS Kesehatan yang dikeluarkan untuk jaminan kesehatan bagi seluruh masyarakat Indonesia dan BPJS Ketenagakerjaan yang dikeluarkan untuk memberikan jaminan perlindungan kepada para pekerja di Indonesia baik untuk usaha formal maupun informal. Akan tetapi sebagian masyarakat merasakan kurang percaya dengan program BPJS karena adanya perbedaan pelayanan yang mereka terima saat menggunakan kartu BPJS dengan tidak menggunakan BPJS, misalnya diterapkannya motode berjenjang yang membuat pasien tidak bisa secara langsung berobat pada rumah sakit yang diinginkan (Pertiwi, 2016).

Pelayanan kesehatan menjadi suatu hal yang utama dan mendasar bagi setiap orang. Sehingga setiap rumah sakit memiliki tanggung jawab untuk menyediakan pelayanan kesehatan yang sesuai dengan kebutuhan masyarakat. Pelayanan bisa dikatakan bermutu jika sudah memenuhi lima dimensi. Bukti Fisik merupakan hal yang nampak nyata diberikan oleh rumah sakit untuk pasiennya; Kehandalan merupakan kemampuan rumah sakit dalam memberikan pelayanan sesuai yang dijanjikan; Daya tanggap merupakan kemampuan untuk membantu melayani pasien dengan baik; Jaminan merupakan kepercayaan pasien atas pelayanan yang mereka terima hingga terbebas dari keraguan; Empati merupakan rasa untuk memberikan perhatian secara personal kepada pasien (Wiguna, 2017).

Salah satu alasan kenapa terjadi perpindahan pelanggan dari penyedia jasa satu ke penyedia jasa lainnya karena adanya pelanggan yang tidak puas dengan penyelesaian masalah yang mereka terima. Ketika konsumen tidak merasa puas atas apa yang diterimanya pada saat menemui masalah dapat membuat mereka berpindah pada penyedia jasa lainnya (Haryanto dan Dewi, 2018). Menurut Friele et al. (2015), pasien mengajukan keluhan karena menginginkan adanya pejelasan tentang apa yang terjadi serta meminta adanya solusi untuk mencegah ketidaknyamanan yang mereka rasakan. Penanganan komplain pasien rumah sakit saat ini menjadi salah satu kunci utama untuk rumah sakit agar terus meningkatkan pelayanannya dan berkembang.

Demikian rumah sakit harus terus menjaga kepercayaan masyarakat dengan terus memperhatikan kualitas pelayanan didukung dengan sarana dan prasarana yang memadai. Rumah sakit perlu cermat menentukan apa yang dibutuhkan oleh masyarakat untuk memenuhi kebutuhan mereka sehingga mereka merasa puas dengan pelayanan yang merka terima dan secara tidak langsung mempengaruhi kesetiaan pelanggan serta dapat berdampak pada citra rumah sakit.

Citra rumah sakit menjadi salah satu faktor penting dalam membentuk kepercayaan pasien terhadap pelayanan yang diberikan. Dengan demikian rumah sakit harus menjaga kepercayaan masyarakat dengan menjaga kualitas pelayanan agar tetap baik (Haryanto dan Dewi, 2018). Hal ini diperkuat oleh hasil penelitian Ma'ruf (2017) dimana terdapat hubungan yang positif dan signifikan antara pelayanan yang meliputi layanan dokter/perawat, layanan fasilitas, layanan administrasi dan keuangan dengan Kepuasan Pasien. Berdasarkan dari uraian latar belakang diatas maka peneliti berpendapat layak melakukan penelitian dengan judul 
Analisis Kualitas Pelayanan, Penanganan Komplain Dan Citra Rumah Sakit Terhadap Kepuasan Pengguna Kartu BPJS Di Rumah Sakit Dr. Oen Surakarta.

Tujuan penulisan ini adalah (1) Menganalisa pengaruh secara simultan kualitas pelayanan, penanganan komplain dan citra terhadap kepuasan pasien BPJS di Rumah Sakit Dr. Oen Surakarta, (2) Mengetahui pengaruh kualitas pelayanan terhadap kepuasan pasien BPJS di Rumah Sakit Dr. Oen Surakarta, (3) Mengetahui pengaruh penanganan komplain terhadap kepuasan pasien BPJS di Rumah Sakit Dr. Oen Surakarta, (4) Mengetahui pengaruh citra rumah sakit terhadap kepuasan pasien BPJS di Rumah Sakit Dr. Oen Surakarta.

\section{TINJAUAN PUSTAKA}

a. Kepuasan Pelanggan

Kepuasan pelanggan merupakan rasa senang ataupun kekecewaan yang mucul setelah mereka membandingkan dan merasakan apa yang mereka terima dengan apa yang mereka angan-angankan terhadap produk ataupun jasa yang mereka gunakan (Chusminah et al, 2018). Karakteristik dalam jasa atau layanan menurut Kotler (2013:37)

1) Intangibility (tidak berwujud)

2) Inseparability (tidak terpisahkan)

3) Variability (bervariasi)

4) Perishability (tidak tahan lama)

b. Kualitas Pelayanan

Menurut Wibowo dan Alwie (2017), kualitas pelayanan dapat diartikan sebagai upaya untuk memenuhi kebutuhan dan keinginan konsumen serta ketepatan penyampaian dalam mengimbangi harapan konsumen. Dimensi Kualitas Pelayanan

1) Wujud Nyata (tangibles)

2) Kehandalan (reliability)

3) Ketanggapan atau kepedulian (responsiveness)

4) Jaminan (assurance)

5) Perhatian (empathy)

c. Penangangan Komplain

Keluhan merupakan hal yang disampaikan oleh konsumen karena mereka merasakan adanya ketidaksesuaian atas jasa yang diterima dengan yang dijanjikan. Suatu pengaduan dan keluhan bisa dijadikan kesempatan untuk perusahaan agar memperbaiki kesalahan yang ada. Dengan demikian, perusahaan dapat mengembangkan ide-ide yang baru, meningkatkan pemasaran ataupun pelayanan. Tujuan Utama Keluhan Konsumen Menurut Lovelock \& Wirtz (2011:118)

1) Mendapatkan Restitusi atau Kompensasi

2) Melampiaskan Kemarahan Mereka

3) Bantuan Untuk Meningkatkan Layanan

4) Alasan Altruistic

d. Citra Perusahaan

Citra perusahaan adalah campuran dari berbagai persepsi dan sikap konsumen terhadap suatu badan usaha. Citra perusahaan memiliki karakteristik yang sama dengan potret diri 
perusahaan itu sendiri dimana dapat mempengaruhi keputusan kosumen. Citra perusahaan akan mencerminkan seberapa besar komitmen organisasi terhadap kualitas dan keunggulan yang dapat membantu konsumen untuk mengetahui tentang produk atau jasa yang ditawarkan (Sudarso, 2016: 50-51). Faktor Pembentuk Citra Menurut Ardianto (2011: 72)

1) Identitas Fisik

2) Identitas Non Fisik

3) Manajemen Organisasi

4) Kualitas Hasil

5) Aktivitas dan Pola Hubungan

\section{METODE PENELITIAN}

Jenis penelitian ini menggunakan metode deskriptif. Populasi dalam penelitian ini adalah seluruh pasien rawat jalan pengguna kartu BPJS yang tidak terhingga dengan menggunakan teknik sampling purposive sampling. Sampel yang diambil sebanyak 100 responden. Metode analisis data yang digunakan adalah regresi linier berganda

\section{HASIL DAN PEMBAHASAN}

a. Uji Asumsi Klasik

1) Uji Normalitas

Hasil pengujian menunujukan bahwa nilai Asymp.Sig (2-tiled) 0,564 atau lebih besar dari 0,05. Maka dapat disimpulkan bahwa persamaan regresi untuk model dalam penelitian ini memiliki data yang normal.

2) Uji Multikolinearitas

Uji multikolinieritas dilakukan untuk mengetahui apakah terdapat korelasi antar variabel bebas. Apabila nilai tolerance $>0,10$ dan VIF $<10$.

\begin{tabular}{|l|l|c|c|c|c|}
\hline \multicolumn{1}{|c|}{ Variabel } & Tolerance & Std & VIF & Std & Kesimpulan \\
\hline Kualitas Pelayanan & 0,826 & $>0,10$ & 1,211 & $<10$ & Tidak ada multikolinieritas \\
\hline $\begin{array}{l}\text { Penanganan } \\
\text { Komplain }\end{array}$ & 0,631 & $>0,10$ & 1,584 & $<10$ & Tidak ada multikolinieritas \\
\hline Citra Rumah Sakit & 0,699 & $>0,10$ & 1,431 & $<10$ & Tidak ada multikolinieritas \\
\hline
\end{tabular}

3) Uji Heterokadastisitas

Uji ini dapat dilakukan dengan cara uji gletser, yaitu meregresi nilai absolut residual terhadap variabel independen. Jika $P_{\text {value }}>0,05$ maka tidak terjadi heteroskedastisitas, sebaliknya jika $P_{\text {value }}<0,05$ maka terjadi heteroskedasitisitas.

\begin{tabular}{|l|c|c|c|}
\hline \multicolumn{1}{|c|}{ Variabel } & P-Value (Sig) & Batas & Kesimpulan \\
\hline Kualitas Pelayanan & 0,521 & $\geq 0,05$ & Tidak terjadi heterokadastisitas \\
\hline Penanganan Komplain & 0,532 & $\geq 0,05$ & Tidak terjadi heterokadastisitas \\
\hline Citra Rumah Sakit & 0,220 & $\geq 0,05$ & Tidak terjadi heterokadastisitas \\
\hline
\end{tabular}


Berdasarkan data tabel diatas dapat disimpulkan bahwa probabilitas value $\mathrm{X}_{1}, \mathrm{X}_{2}$ dan $\mathrm{X}_{3}$, lebih besar (>) 0,05 yang berarti tidak signifikan, sehingga dapat diartikan bahwa data berasal dari varians sama dan tidak terjadi heteroskedastisitas.

b. Analisis Regresi Linier Berganda

\begin{tabular}{|l|c|c|}
\hline \multirow{2}{*}{ Variabel } & \multicolumn{2}{|c|}{ Unstandardized Coefficients } \\
\cline { 2 - 3 } & $\mathrm{B}$ & Std.Eror \\
\hline Constant & 0,933 & 2.414 \\
\hline Kualitas Pelayanan & 0,377 & 0,036 \\
\hline Penanganan Komplain & 0,053 & 0,074 \\
\hline Citra Rumah Sakit & 0,018 & 0,124 \\
\hline
\end{tabular}

Maka dapat disusun analisis regresi sebagai berikut :

$\mathrm{Y}=0,933+0,377 X_{1}+0,053 X_{2}+0,018 X_{3}+\mathrm{e}$

Dari persamaan regresi tersebut dapat diinterpretasikan sebagai berikut:

1) Nilai konstanta sebesar 0,933 menunjukan bahwa jika semua variabel independen nilainya 0 , maka kepuasan akan meningkat sebesar 0,933 .

2) Nilai koefisien variabel kualitas pelayanan $\left(b_{1}\right)$ dari perhitungan regresi linier berganda nilai coefficients (b) sebesar 0,377, artinya jika kualitas pelayanan meningkat satu, sementara variabel penanganan komplain dan citra rumah sakit tetap (nol), maka kepuasan akan meningkat sebesar 0,377.

3) Nilai koefisien variabel penanganan komplain $\left(b_{2}\right)$ dari perhitungan regresi linier berganda nilai coefficients (b) sebesar 0,053, artinya jika penanganan komplain meningkat satu satuan, sementara variabel kualitas pelayanan dan citra rumah sakit tetap (nol), maka kepuasan akan meningkat sebesar 0,053.

4) Nilai koefisien variabel citra rumah sakit $\left(b_{3}\right)$ dari perhitungan regresi linier berganda nilai coefficients (b) sebesar 0,018, artinya jika citra rumah sakit meningkat satu satuan, sementara variabel kualitas pelayanan dan penanganan komplain tetap (nol), maka kepuasan akan meningkat sebesar 0,018 .

c. Uji Hipotesis

1) Uji F

Uji $\mathrm{F}$ digunakan untuk mengetahui apakah semua variable independent yang ada pada penelitian memiliki pengaruh secara bersamaan terhadap variable dependent. Menurut hasil analisis maka diketahui nilai Fhitung > Ftabel (48,524 > 2,70) dan signifikansi $0,000<0,05$ maka Ho ditolak. Kesimpulan Ha diterima, artinya kualitas pelayanan, penanganan komplain dan citra rumah sakit berpengaruh secara simultan dan signifikan terhadap kepuasan pengguna kartu BPJS di Rumah Sakit Dr. Oen Surakata.

2) $\mathrm{Uji} \mathrm{t}$

Menurut hasil analisis maka diketahui

a) Variabel kualitas pelayanan $\left(\mathrm{X}_{1}\right)$ diperoleh nilai $\mathrm{t}_{\text {hitung }}$ sebesar 10,555 sedangkan besar $\mathrm{t}_{\text {tabel }}$ adalah 0,677 ( $\left.\mathrm{t}_{\text {hitung }}>\mathrm{t}_{\text {tabel }}\right)$ dengan signifikansi $5 \%($ sig $0,000<0,05)$ sehingga 
dapat disimpulkan bahwa Ho ditolak berarti ada pengaruh signifikan kualitas pelayanan $\left(\mathrm{X}_{1}\right)$ terhadap kepuasan pengguna BPJS.

b) Variabel penanganan komplain $\left(\mathrm{X}_{2}\right)$ diperoleh nilai thitung sebesar 0,713 sedangkan besar $t_{\text {tabel }}$ adalah 0,677 ( $t_{\text {hitung }}>\mathrm{t}_{\text {tabel }}$ ) dengan signifikansi 5\% (sig 0,478>0,05) sehingga dapat disimpulkan bahwa Ho diterima berarti tidak ada pengaruh signifikan penanganan komplain $\left(\mathrm{X}_{2}\right)$ terhadap kepuasan pengguna BPJS.

c) Variabel penanganan komplain $\left(\mathrm{X}_{2}\right)$ diperoleh nilai $\mathrm{t}_{\text {hitung }}$ sebesar 0,713 sedangkan besar $\mathrm{t}_{\text {tabel }}$ adalah 0,143 ( $\mathrm{t}_{\text {hitung }}<\mathrm{t}_{\text {tabel }}$ ) dengan signifikansi 5\% (sig 0,887>0,05) sehingga dapat disimpulkan bahwa Ho diterima berarti tidak ada pengaruh signifikan citra rumah sakit $\left(\mathrm{X}_{3}\right)$ terhadap kepuasan pengguna BPJS

d. Koefisien Determinasi $\left(R^{2}\right)$

Nilai $\mathrm{R}^{2}$ sebesar 0,590 atau 59\%, artinya bahwa variabel kualitas pelayanan, penanganan komplain dan citra rumah sakit mempunyai pengaruh sebesar 59\% terhadap kepuasan pengguna kartu BPJS di rumah sakit Dr. Oen Surakarta sisanya sebesar $41 \%$ dipengaruhi oleh variabel lain di luar penelitian ini

e. Pembahasan

1) hasil analisis uji $F$ melalui program SPSS diperoleh nilai $F_{\text {hitung }} 48,524>$ dari $F_{\text {tabel }} 2,70$ atau nilai signifikan 0,000 $<0,05$ sehingga Ho ditolak. Maka variabel kualitas pelayanan $\left(\mathrm{X}_{1}\right)$, penanganan komplain $\left(\mathrm{X}_{2}\right)$, dan citra rumah sakit $\left(\mathrm{X}_{3}\right)$ secara bersama-sama berpengaruh signifikan terhadap kepuasan pengguna kartu BPJS (Y).

2) Pengaruh kualitas pelayanan terhadap kepuasan pengguna kartu BPJS

Diperoleh $t_{\text {hitung }}>t_{\text {tabel }}(10,555>0,677)$ dan nilai signifikansi $0,000<0,05$ yang menunjukkan bahwa kualitas pelayanan mempunyai pengaruh dan siginifikan terhadap kepuasan. Kualitas pelayanan pada rumah sakit Dr. Oen Surakarta sudah memiliki standar yang baik dari lima dimensi yang ada.

3) Pengaruh penanganan komplain terhadap kepuasan pengguna kartu BPJS

Diperoleh $t_{\text {hitung }}>t_{\text {tabel }}(0,713>0,677)$ dan nilai signifikansi $0,478>0,05$ yang menunjukkan bahwa penanganan komplain tidak berpengaruh terhadap kepuasan pengguna kartu BPJS di rumah sakit Dr. Oen Surakarta dikarenakan minimnya keluhan dari pasien mengenai pelayanan yang diberikan oleh rumah sakit.

4) Pengaruh citra rumah sakit terhadap kepuasan pengguna kartu BPJS

Diperoleh $t_{\text {hitung }}>t_{\text {tabel }}(0,143<0,677)$ dan nilai signifikansi $0,887>0,05$ yang menunjukkan bahwa citra rumah sakit tidak berpengaruh dan siginifikan terhadap kepuasan pengguna kartu BPJS dikarenakan sistem berjenjang yang diberlakukan oleh BPJS membuat pengguna kartu tidak bisa memilih rumah sakit mana yang akan mereka tuju.

\section{KESIMPULAN DAN SARAN}

a. Kesimpulan

Berdasarkan hasil analisis dan pembahasan diatas mengenai pengaruh kualitas pelayanan, penanganan komplain dan citra rumah sakit terhadap kepuasan pengguna kartu BPJS di rumah sakit Dr. Oen Surakarta. Maka penulis dapat menarik kesimpulan sebagai berikut : 
1) Variabel kualitas pelayanan, penanganan komplain dan citra rumah sakit bepengaruh secara simultan terhadap kepuasan pengguna kartu BPJS di rumah sakit Dr. Oen Surakarta.

2) Kualitas pelayanan berpengaruh secara parsial dan signifikan terhadap kepuasan pengguna kartu BPJS di rumah sakit Dr. Oen Surakarta.

3) Penanganan komplain tidak berpengaruh secara parsial dan signifikan terhadap kepuasan pengguna kartu BPJS di rumah sakit Dr. Oen Surakarta.

4) Citra rumah sakit tidak berpengaruh secara parsial dan signifikan terhadap kepuasan pengguna kartu BPJS di rumah sakit Dr. Oen Surakarta.

b. Saran

Kualitas pelayanan merupakan variabel yang paling dominan mempengaruhi kepuasan pengguna kartu BPJS di rumah sakit Dr. Oen Surakarta. Untuk itu akan lebih baik rumah sakit Dr. Oen Surakarta tetap terus meningkatkan kualitas pelayanan yang sudah ada dengan memperhatikan kritik dan saran dari pasien sebagai bahan introspeksi supaya lebih berkualitas serta sesuai dengan peraturan yang berlaku.

\section{DAFTAR PUSTAKA}

Chusminah. (2018). Pengaruh Kualitas Pelayanan Kesehatan Terhadap Kepuasan Pasien Peserta BPJS di Rumah Sakit Umum (RSUD) Kota Bekasi. Aktiva - Jurnal Penelitian Ekonomi dan Bisnis. Vol 2. No. 1 Juli 2018. E-issn : 2598 - 5256

Elvinaro, A. (2011). Metodologi Penelitian untuk Public Relations Kuantitatif dan Kualitatif. Bandung: Simbiosa Rekatama Media

Friele D. Roland, Reitsma P. M. and de Jong J. D. (2015). Complaint handling in healthcare: Expectation gaps between physicians and the public. Results of a survey study. BMC Research. DOI: 10.1186/s13104-015-1479-z

Haryanto T. Aris dan Dewi N. Septiana. (2018). Peran Mediator Kepuasan Untuk Mengaloborasi Kualitas Pelayanan, Citra dan Penanganan Komplain Terhadap Loyalitas (Studi Pasien BPJS di Rumah Sakit Islam Amal Sehat Sragen. Jurnal Perilaku Dan Strategi Bisnis. Vol.6 No.1, 2018 Hal. 1-8

Kotler, Philip., Keller, Kevin L. (2013). Manajemen Pemasaran. Jilid 2. Jakarta: Erlangga

Lovelock \& Wirtz. 2011. Services Marketing: People, Technology, Strategy. Seventh Edition. England: Pearson Education Limited

Ma'ruf, M. H. (2016). Analisis Pengaruh Kualitas Pelayanan Terhadap Kepuasan Pasien Pada Rumah Sakit Umum Daerah Sukoharjo. Jurnal Akuntansi dan Pajak, 16(02). 
Mongkaren, Steffi. (2013). Fasilitas dan Kualitas Pelayanan Pengaruhnya Terhadap Kepuasan Penguna Jasa Rumah Sakit Advent Manado. Jurnal EMBA. Vol.1 No.4 Desember 2013, Hal. 493-503. ISSN 2303-1174

Pertiwi, A. N Aisah. (2016). Analisis Perbedaan Kualitas Pelayanan Pada Pasien Bpjs Dan Pasien Umum Terhadap Kepuasan Pasien Di Rawat Jalan Rsud Kota Surakarta. Daya Saing Jurnal Ekonomi Manajemen Sumber Daya Vol. 18, No. 2, Desember 2016

Sharon G. Lyrissa \& Santoso B. Suryono. (2017). Analisis Pengaruh Kualitas Layanan, Fasilitas, Citra Rumah Sakit, Kepuasan Pasien Dalam Rangka Meningkatkan Loyatias Pasien. Diponegoro Journal of Management. Volume 6, No 3, 2017 Hal. 1-12. ISSN (Online): 2337-3792

Sudarso , A. (2016). Manajemen Jasa Perhotelan. Yogyakarta: Deepublish

Wibowo A. Anom \& Alwie F. Alvi. (2017). Analisis Kualitas Pelayanan Terhadap Kepuasan dan Loyalitas Peserta BPJS Kesehatan di RSUD Arifin Achmad Pekanbaru. Jurnal Tepak Manajemen Bisnis. Vol. IX. No. 3. September 2017

Wiguna S. Ary. (2017). Hubungan Mutu Pelayanan BPJS Kesehatan Dengan Kepuasan Pasien BPJS di Instalasi Rawat Inap Kelas II di RSU Imelda Medan. Jurnal Ilmiah Perekam Dan Informasi Kesehatan Imelda. Vol 2. No. 1, Februari 2017 